\title{
MOLECULAR MODELING OF INTERACTIONS BETWEEN CATALYTIC NANOPARTICLES AND POLYMER CARRIERS
}

\author{
1,2Adam VERNER, ${ }^{1,3,4}$ Jonáš TOKARSKÝ \\ ${ }^{1}$ Nanotechnology Centre, VŠB - Technical University of Ostrava, Ostrava, Czech Republic, EU, \\ adam.verner@vsb.cz, jonas.tokarsky@vsb.cz \\ ${ }^{2} E N E T$ Centre, VŠB - Technical University of Ostrava, Ostrava, Czech Republic, EU, adam.verner@vsb.cz \\ 3/T4Innovations, VŠB - Technical University of Ostrava, Ostrava, Czech Republic, EU, \\ jonas.tokarsky@vsb.cz \\ 4Institute of Environmental Technology, VŠB - Technical University of Ostrava, Ostrava, Czech Republic, \\ EU, jonas.tokarsky@vsb.cz
}

https://doi.org/10.37904/nanocon.2020.3772

\begin{abstract}
Nowadays, the scientific and technological field is at a very high level, which is related, among other things, to the large production of various products, and this unfortunately brings a high degree of environmental threat. For example, highly hazardous gases might be released into the environment accidentally, therefore a solution to these dangerous situations needs to be found. A research is conducted into cerium(IV) oxide, platinum, and palladium nanoparticles (NPs), which have been found to have hazardous gases degrading properties. This work complements this field by studying the interactions between NPs and their potential polymer nanofiber carriers, polyamide 6 (PA) and $\beta$-polyvinylidene fluoride (PVDF). In order to determine the suitability of these carriers, molecular modeling (geometry optimization using COMPASS forcefield) was involved. Interaction energies (Eint) between the most occupied (hkl) planes of NPs ((100), (110), (111), and (311)) and different (hkl) planes of PA and PVDF surfaces ((001), (100) and (010), (001), (00-1), respectively) were determined. Although all types of NPs showed attractive interactions with all types of surfaces, preferred orientations are clearly identifiable. Attention was focused on the possible influence of the NPs interlayer distance $\mathrm{d}_{\mathrm{hkl}}$ on the resulting Eint.
\end{abstract}

Keywords: Nanofiber, nanoparticle, molecular modeling, interaction energy, COMPASS

\section{INTRODUCTION}

Today, the scientific and technical field is at a very high level, which is associated not only with new advanced knowledge of the biological, chemical and physical nature of environment or large number of high quality products, but also with enormous environmental impact [1]. In this regard, attention should be focused, among other things, on the development of systems and methods that eliminate pollutants from the gas and liquid phases. The use of nanoparticles and nanofibers has proven to be effective due to their interactivity based on their specific properties. In the case of nanofibers, primarily small pore sizes are used and the principle of filtration thus consists in the impermeability of undesirable particles. Nanoparticles work on the principle of chemical interaction with pollutants, which either capture or degrade [2]. Nowadays, cerium(IV) oxide, palladium and platinum nanoparticles are frequently studied due to its catalytic and antioxidant properties with the potential to degrade hazardous gases in the air [3,4]. Interactions between nanofiber layers formed of polyamide 6 (PA) or poly(vinylidene fluoride) (PVDF) and incorporated $\mathrm{CeO}_{2}\left(\mathrm{CeO}_{2}\right)$, palladium ( $\mathrm{Pd}$ ) and platinum (Pt) nanoparticles (NP) are investigated using molecular modeling. 


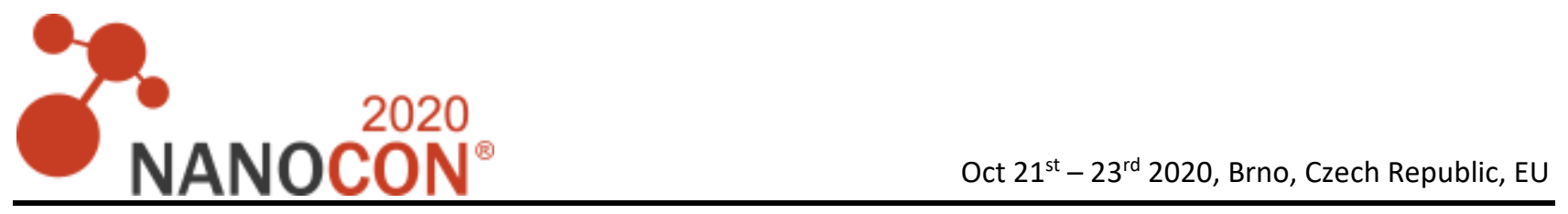

\section{MATERIALS AND METHODS}

\subsection{Preparation of models}

In this study, Biovia Materials Studio 7.0 (MS) modeling environment was used [5]. Unit cells of $\mathrm{CeO}_{2}$ (lattice parameter $\left.a=b=c=5.411 \AA, \alpha=\beta=\gamma=90^{\circ}\right), \operatorname{Pt}\left(a=b=c=3.924 \AA, \alpha=\beta=\gamma=90^{\circ}\right), P d(a=b=c=3.891$ $\AA, \alpha=\beta=\gamma=90^{\circ}$ ) were taken from the MS structures database.

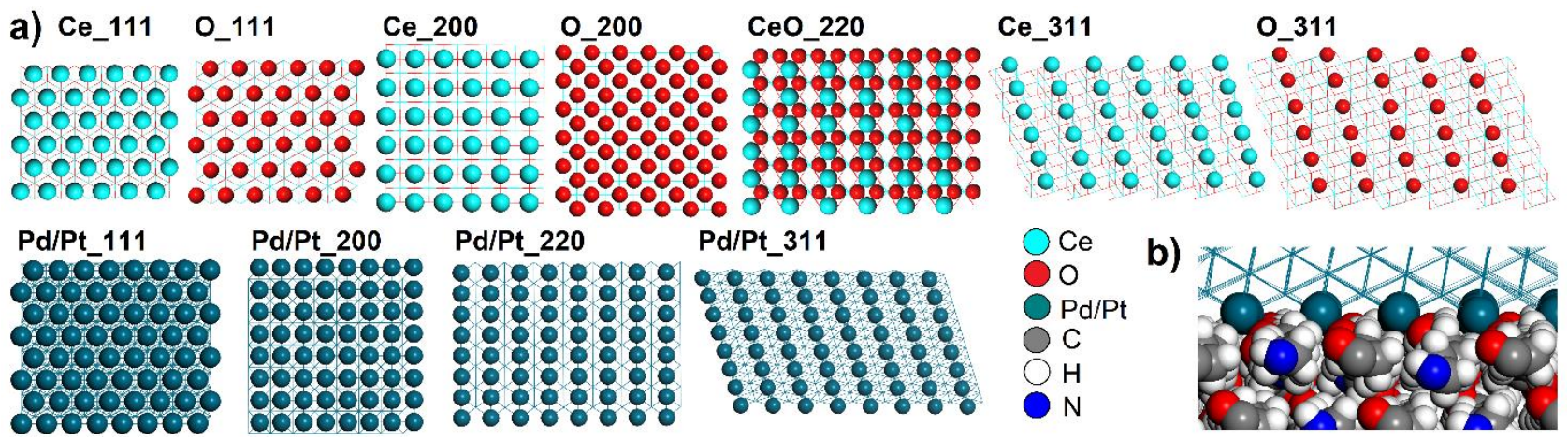

Figure 1 a) View of $\mathrm{CeO}_{2}$ and $\mathrm{Pd} / \mathrm{Pt} \mathrm{NP}$ bases made by cleaving unit cells along different ( $\mathrm{h} \mathrm{k}$ l) planes.

b) The model of Pd/Pt_311_0 lying on PA_001 with the polymer chains penetrating gaps between the lines of Ce atoms.

$\mathrm{CeO}_{2}, \mathrm{Pd}$, and Pt NP models were created by cleaving the periodic structures along ( $\mathrm{h} \mathrm{l}$ ) planes with the highest atom occupation (according to XRD analysis in MS) - these are ( $\mathrm{h} \mathrm{k} \mathrm{I}$ ) planes (2 00 ), (2 20 ), (1 111 ),

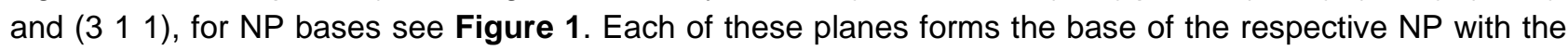
size given by the number of surface atoms $\left(6 \times 6 \mathrm{Ce}\right.$ atoms in the case of $\left.\mathrm{CeO}_{2} \mathrm{NPs}\right)$. The height of the NP was determined so that the total number of atoms in NP was 594. $\mathrm{CeO}_{2} \mathrm{NPs}$ had $\mathrm{Ce}, \mathrm{O}$ atoms or both atom types forming bases. $\mathrm{CeO}_{2}$ NPs were denoted as Ce_200 (NP base cleaved along (2 0 0) plane and formed with $\mathrm{Ce}$ atoms), O_200, Ce_111, O_111, Ce_311, O_311, and NPs containing both $\mathrm{Ce}$ and $\mathrm{O}$ atoms in their base were denoted as $\mathrm{CeO} \_220$. Pd and Pt NPs were denoted as Pd_200, Pd_220,Pd_111, Pd_311, and Pt_200, Pt_220, Pt_111, Pt_311, respectively.

Monoclinic unit cell of $\beta$-polyamide 6 (PA) [6], having parameters $a=16.88 \AA, b=4.78 \AA, c=9.33 \AA, \alpha=90^{\circ}$, $\beta=67.5^{\circ}, y=90^{\circ}$, was obtained from the Cambridge structural database [7]. 2D models of PA surfaces were prepared by cleaving the cell along $\left(\begin{array}{lll}0 & 0 & 1\end{array}\right)$ plane $(22 \mathrm{H}+2 \mathrm{O}$ atoms per unit cell perpendicular to the plane; Figure 2) and (1 00 ) plane ( $20 \mathrm{H}$ atoms per unit cell perpendicular to the plane; Figure 2).

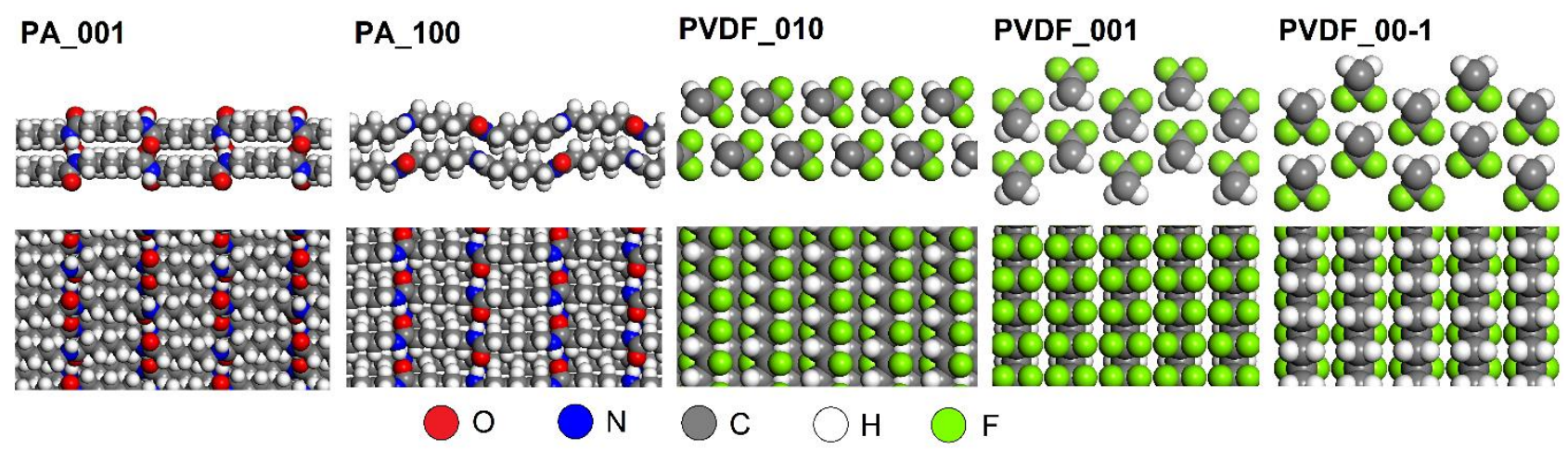

Figure 2 View of PA and PVDF surfaces made by cleaving unit cells along different planes. Side view (top) and vertical view (bottom) of PA_001, PA_100, PVDF_010, PVDF_001 and PVDF_00-1. 
Orthorhombic unit cell of $y$-poly(vinylidene fluoride) (PVDF), having parameters $a=2.56 \AA, b=4.91 \AA, c=$ $8.58 \AA, \alpha=\beta=\gamma=90^{\circ}$, was prepared according to the research by Hasegawa et al. [8]. 2D models of PVDF surfaces were prepared by cleaving the cell along $\left(\begin{array}{lll}0 & 1 & 0\end{array}\right)$ plane $(\mathrm{H}$ and $\mathrm{F}$ atoms perpendicular to the plane; Figure 2), $\left(\begin{array}{lll}0 & 0 & 1\end{array}\right)$ plane ( $F$ atoms perpendicular to the plane; Figure 2) and $\left(\begin{array}{lll}0 & 0 & -1\end{array}\right)$ plane $(\mathrm{H}$ atoms perpendicular to the plane; Figure 2).

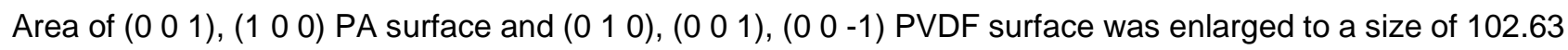
$\times 101.28 \AA, 101.28 \times 100.38 \AA$ and $98.2 \times 99.84 \AA, 99.84 \times 102.96 \AA, 102.96 \times 99.84 \AA$, respectively. Vacuum slab of height $400 \AA$ was added perpendicular to each surface. Models of periodic cells containing PA and PVDF surfaces were denoted as PA_001, PA_100 and PVDF_010, PVDF_001, PVDF_00-1, respectively.

Models were prepared by placing single NP in the center of PA or PVDF surfaces oriented with the base parallel to the polymer surfaces and different rotations to polymer chains of the surfaces. 9 models were prepared for each NP type on each polymer surface type.

\subsection{Modeling conditions}

Geometry optimization of each model was performed in MS/Forcite module. Atoms in models were parameterized and their charges were assigned by COMPASS force field [9].

Smart algorithm as implemented in MS with $5 \cdot 10^{5}$ steps was used. Convergence thresholds for the maximum energy and maximum force changes were $1 \cdot 10^{-4} \mathrm{kcal} / \mathrm{mol}$ and $5 \cdot 10^{-3} \mathrm{kcal} / \mathrm{mol} / \AA \AA$, respectively [10]. For the Coulombic and the van der Waals forces, atom based summation method as implemented in MS was used. The cell parameters were not optimized. For each model, interaction energy ( $E_{\text {int }}$ ) was calculated from potential energies $\left(E_{p}\right)$ using the following equation (all energies are in $\mathrm{kcal} / \mathrm{mol}$ ):

$E_{\text {int }}=E_{p 1}-E_{p 2}-E_{p 3}$

where:

$E_{p 1}-E_{p}$ of whole model

$E_{p 2}-E_{p}$ of PA or PVDF surface without the NP

$E_{p 3}-E_{p}$ of the NP without the PA or PVDF surface

\section{RESULTS AND DISCUSSION}

Interaction energies between the NPs and PA and PVDF surfaces of nanofibers do not depend on the rotation of the NP bases on the polymer surfaces (except of Pd_311 and Pt_311, see below).The main factor determining average interaction energies of models ( $E_{\text {int }}$ ) was the size of the NP base (S) adjacent to the polymer surfaces. The larger the $\mathrm{S}$, the higher the number of interatomic interactions between the NPs and the surfaces, resulting in lower Eint. Among models with PA and PVDF surfaces, the lowest Eint was obtained for Ce_311 lying on PA_001 (Eint = -13 $240 \mathrm{kcal} / \mathrm{mol}$ ) and PVDF_001 (Eint $=-18924 \mathrm{kcal} / \mathrm{mol})$, respectively. In order to determine interaction energies of models irrespective of the size of the NP base S, Eint of the models were divided by $S$ and interaction energies (Eints) were thus related to one square nanometer $\left(\mathrm{kcal} / \mathrm{mol} / \mathrm{nm}^{2}\right)$ (Figures 3a and 3b).

$E_{\text {int/s }}$ is related to the distance between atomic layers $\left(d_{h k l}\right)$ of the NPs. The larger the $d_{h k l}$, the lower Eints it shows with PA or PVDF surfaces (Figures 3a and 3b). The largest $d_{\text {hkl }}\left(C e \_111,0 \_111, P d \_111\right.$ and Pt_111) provides the greatest specificity of each atomic layer charge, which also refers to the longest, and therefore weakest, atomic bonds between the atomic layers thanks to which the NPs are able to make stronger noncovalent intermolecular attractive interactions with the polymer surfaces. 

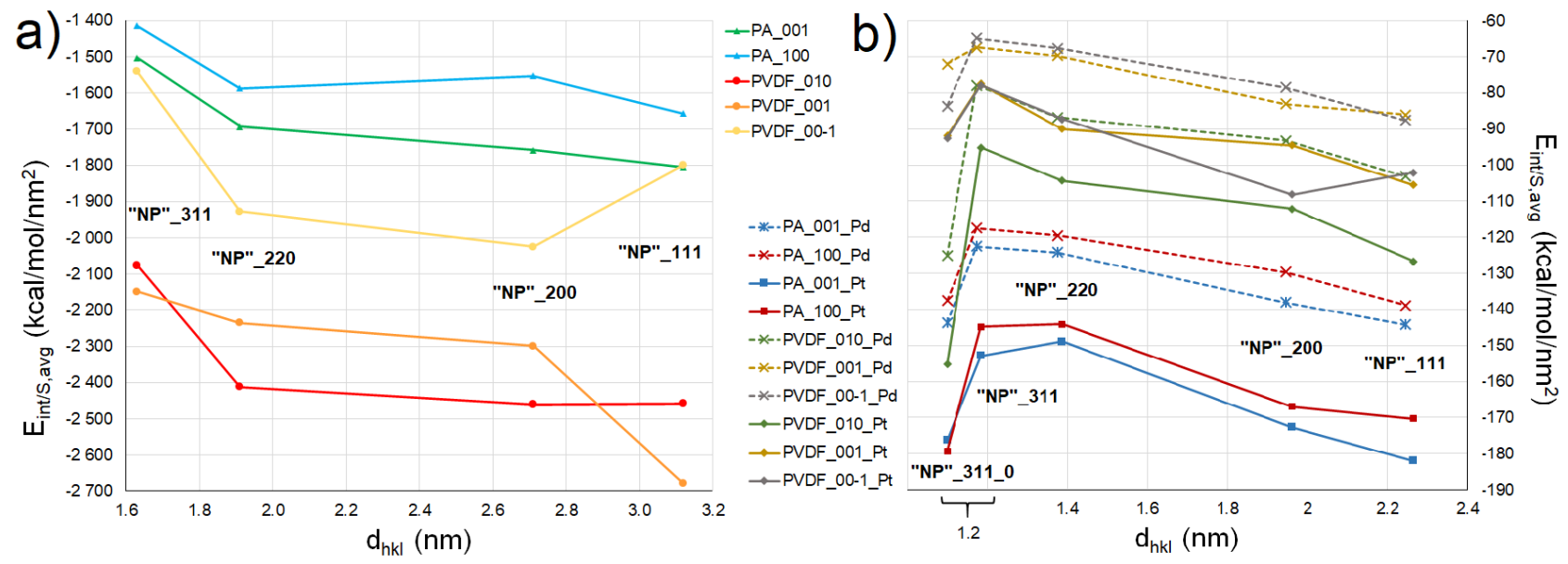

Figure 3 The interaction energy $E_{i n t / s}$ dependence on the distance $d_{h k l}$ of a) $\mathrm{CeO}_{2} \mathrm{NPs}$ and b) Pd and Pt NPs lying on PA and PVDF surfaces. "NP" refers to the NP denotations according to the contact atoms in the base, i.e., a) $\mathrm{Ce}, \mathrm{O}$ or $\mathrm{CeO}$, b) $\mathrm{Pd}$ or Pt.

Interactions of $\mathrm{CeO}_{2}$ NPs lying on PVDF surfaces are $34 \%$ stronger than on PA surfaces, however Pd and Pt NPs interact more strongly by $60 \%$ with PA surfaces than with PVDF surfaces (Figures $3 \mathbf{a}$ and $\mathbf{3 b}$, Tables 1 and 2). Since $\mathrm{CeO}_{2}$ is a binary compound (Figure 1), partial charges and thus polarity are shown on atoms, which provides stronger interactions with polar chains of the surface. Pd and Pt are elements (Figure 1), so there is no polarity. PA chains are characterized by polar (peptide bonds - $\mathrm{COHN}-$ ) and nonpolar (aliphatic) parts alternation (Figure 2), while the polarity direction of PVDF chains is perpendicular to the chain axis (one side of the chain forms bonds with $\mathrm{F}$ atoms, the other one with $\mathrm{H}$ atoms; Figure 2). Therefore, stronger polar interactions with PVDF surfaces occur in the case of $\mathrm{CeO}_{2}$, while Pd and Pt NPs interact more strongly with PA surfaces due to the presence of nonpolar aliphatic parts of PA chains (Table1).

Table 1 Average interaction energies $E_{\text {int/s,avg }}$ of all models with PA or PVDF surfaces containing every NP type with information of NP base compositions $\left({ }^{*}-\right.$ structures with the lowest $\left.E_{\text {ints, avg }}\right)$

\begin{tabular}{|c|c|c|c|c|c|c|c|}
\hline $\begin{array}{c}\mathrm{CeO}_{2} \\
\mathrm{NP}\end{array}$ & $\begin{array}{c}\text { NP base } \\
\text { composition } \\
\text { per } \mathrm{nm}^{2}\end{array}$ & $\begin{array}{c}\text { PA E } E_{\text {int/s,avg }} \\
(\mathbf{k c a l} / \\
\left.\mathrm{mol} / \mathrm{nm}^{2}\right)\end{array}$ & $\begin{array}{c}\text { PVDF E } \text { Ents,avg } \\
(\mathrm{kcal} / \\
\left.\mathrm{mol} / \mathrm{nm}^{2}\right)\end{array}$ & $\begin{array}{c}\mathrm{Pd} / \mathrm{Pt} \\
\mathrm{NP}\end{array}$ & $\begin{array}{c}\text { NP base } \\
\text { composition } \\
\text { per } \mathrm{nm}^{2}\end{array}$ & $\begin{array}{c}\text { PA E } E_{\text {int/s,avg }} \\
(\mathrm{kcal} / \\
\left.\mathrm{mol} / \mathrm{nm}^{2}\right)\end{array}$ & $\begin{array}{c}\text { PVDF E } \text { int/s,avg } \\
(\mathrm{kcal} / \\
\left.\mathrm{mol} / \mathrm{nm}^{2}\right)\end{array}$ \\
\hline Ce_111 & $7.9 \mathrm{Ce}$ & $-1842 \pm 72$ * & $-2846 \pm 94$ * & Pd_111 & $17.5 \mathrm{Pd}$ & $-142 \pm 3$ & $-92 \pm 6$ \\
\hline O_111 & 7.90 & $-1619 \pm 67$ & $-2291 \pm 79$ & Pd_200 & $14.8 \mathrm{Pd}$ & $-134 \pm 3$ & $-85 \pm 7$ \\
\hline Ce_200 & $6.8 \mathrm{Ce}$ & $-1659 \pm 74$ & $-2673 \pm 77$ & Pd_220 & $10.5 \mathrm{Pd}$ & $-122 \pm 6$ & $-75 \pm 7$ \\
\hline O_200 & $13.7 \mathrm{O}$ & $-1651 \pm 72$ & $-2086 \pm 149$ & Pd_311 & $8.9 \mathrm{Pd}$ & $-120 \pm 10$ & $-70 \pm 13$ \\
\hline CeO_220 & $4.8 \mathrm{Ce}+9.7 \mathrm{O}$ & $-1639 \pm 61$ & $-2323 \pm 139$ & Pd_311_0 & 8.9 Pd & $-144 \pm 3^{*}$ & $-94 \pm 2$ * \\
\hline Ce_311 & $4.1 \mathrm{Ce}$ & $-1467 \pm 45$ & $-2167 \pm 72$ & Pt_111 & $17.2 \mathrm{Pt}$ & $-176 \pm 5$ & $-111 \pm 6$ \\
\hline \multirow[t]{4}{*}{ O_111 } & 3.40 & $-1452 \pm 62$ & $-2057 \pm 61$ & Pt_200 & 14.6 Pt & $-173 \pm 5$ & $-105 \pm 9$ \\
\hline & & & & Pt_220 & $10.4 \mathrm{Pt}$ & $-147 \pm 7$ & $-94 \pm 10$ \\
\hline & & & & Pt_311 & 8.7 Pt & $-149 \pm 14$ & $-84 \pm 16$ \\
\hline & & & & Pt_311_0 & 8.7 Pt & $-178 \pm 2$ * & $-113 \pm 4$ * \\
\hline
\end{tabular}

$\mathrm{CeO}_{2} \mathrm{NPs}$ exhibits lower Eint/s on PA_001 in comparison with PA_100 (Figure 3a). In the case of $\mathrm{CeO}_{2}$ NPs on PA_001, average interaction energy of all NP types $\left(E_{\text {int }}\right.$ s,avg $)$ is $8 \%$ lower than on PA_100. This is because PA_001 contains $15.9 \mathrm{H}$ and $1.4 \mathrm{O}$ atoms per $\mathrm{nm}^{2}$ in the upper layer of the surface, while PA_100 has there 
only $12.1 \mathrm{H}$ atoms (Table 2), which means different interacting atoms number resulting in different $E_{\text {int/s,avg. }}$ Among PA surfaces, model with the lowest $E_{\text {int } / \mathrm{S}}\left(-1904 \mathrm{kcal} / \mathrm{mol} / \mathrm{nm}^{2}\right)$ contains Ce_111 lying on PA_001.

Table 2 Average interaction energies $E_{\text {int/s,avg }}$ of all models with $\mathrm{CeO}_{2}$, Pd or Pt NPs lying on PA_001, PA_100, PVDF_010 or PVDF_001 surfaces with contact atoms of PA and PVDF surfaces ( ${ }^{*}-$ structures with the lowest Eint/s,avg)

\begin{tabular}{|c|c|c|c|c|}
\hline $\begin{array}{l}\text { polymer } \\
\text { surface }\end{array}$ & $\begin{array}{l}\text { contact atoms } \\
\text { per } \mathrm{nm}^{2}\end{array}$ & $\begin{array}{c}\mathrm{CeO}_{2} \mathrm{E}_{\text {int/s,avg }} \\
\left(\mathrm{kcal} / \mathrm{mol} / \mathrm{nm}^{2}\right)\end{array}$ & $\begin{array}{c}\mathrm{Pd} \mathrm{E}_{\text {int/s,avg }}(\mathrm{kcal} / \\
\left.\mathrm{mol} / \mathrm{nm}^{2}\right)\end{array}$ & $\begin{array}{c}\text { Pt } E_{\text {ints, avg }}(\mathrm{kcal} / \\
\left.\mathrm{mol} / \mathrm{nm}^{2}\right)\end{array}$ \\
\hline PA_001 & $15.9 \mathrm{H}+1.4 \mathrm{O}$ & $-1628 \pm 200$ & $-134 \pm 31$ * & $-166 \pm 38$ * \\
\hline PA_100 & 12.10 & $-1495 \pm 181$ & $-128 \pm 30$ & $-159 \pm 39$ \\
\hline PVDF_010 & $8 \mathrm{~F}+8 \mathrm{H}$ & $-2213 \pm 353$ & $-94 \pm 27$ & $-115 \pm 35$ \\
\hline PVDF_001 & $9.1 \mathrm{~F}$ & $-2244 \pm 474$ * & $-77 \pm 15$ & $-93 \pm 20$ \\
\hline PVDF_00-1 & $9.1 \mathrm{H}$ & $-1744 \pm 291$ & $-76 \pm 18$ & $-95 \pm 20$ \\
\hline
\end{tabular}

In the case of $\mathrm{CeO}_{2}$ on PVDF surfaces, Eint/s trends are different for each surface type (Figure 3a). Models with $\mathrm{CeO}_{2}$ NP on PVDF_010 and PVDF_001 have comparable Eints,avg (Table 2), which is $22 \%$ lower than on PVDF_00-1. This is due to the fact, that the upper layer of PVDF_010 and PVDF_001 contains F atoms providing strong hydrogen bonds with $\mathrm{Ce}$ atoms of the NP, because of the highest difference in electronegativities ( $\mathrm{Ce}-\mathrm{F}=2.86$ [11]) within the possible interacting atomic pairs. For comparison according to atomic pair denotation "NP - polymer surface": $\mathrm{Ce}-\mathrm{H}=1.08, \mathrm{O}-\mathrm{F}=0.54$ and $\mathrm{O}-\mathrm{H}=1.24$. All chains in the upper layer of PVDF_010 interact with the NP, but only a half of the interacting atoms are $F$ (Figure 2), which results in more interacting atoms but less $\mathrm{F}$ atoms per $\mathrm{nm}^{2}$. In the case of PVDF_001, all atoms in the upper layer are F, but only a half of the chains are available for interactions with NP (Figure 2), which is less interacting atoms but more $\mathrm{F}$ atoms per $\mathrm{nm}^{2}$. In the case of PVDF surfaces, the model containing Ce_111 lying on PVDF_001 exhibits the lowest $E_{\text {int } / \mathrm{S}}\left(-3073 \mathrm{kcal} / \mathrm{mol} / \mathrm{nm}^{2}\right)$ due to strong interactions between positive Ce atoms (of $\mathrm{Ce} \_111$ ) and negative $\mathrm{F}$ atoms (of PVDF_001). Models containing $\mathrm{CeO}_{2} \mathrm{NP}$ lying on PVDF_00-1 exhibits different $E_{\text {ints }}$ trends (Figure $\mathbf{3 a}$ ) due to the $\mathrm{H}$ atoms forming upper surface layer (Figure 2). O_200 lying on PVDF_00-1 shows the lowest Eints. Regarding to PVDF_00-1 having formed the upper layer from $\mathrm{H}$ atoms (Figure 2), previous result corresponds to making stronger interactions with $\mathrm{O}$ atoms of the NP instead of $\mathrm{Ce}$ atoms according to influence of electronegativity difference $(\mathrm{O}: \mathrm{H}=1.24>\mathrm{Ce}: \mathrm{H}=1.08)$. $\mathrm{O}$ atoms number of the NP base has another impact on $E_{\text {int/s }}$ besides atomic layer distance dhkl. O_200 has the second highest $\mathrm{d}_{\mathrm{hkl}}\left(\mathrm{O} \mathrm{O}_{111}\right.$ has the first) and the base contains $13.7 \mathrm{O}$ atoms, while $\mathrm{O}$-111 base contains $7.9 \mathrm{O}$ atoms per $\mathrm{nm}^{2}$ (Table 2), which provides more attractive polar interactions and consequently lower Eints. Model with the lowest $E_{\text {ints }}\left(-2467 \mathrm{kcal} / \mathrm{mol} / \mathrm{nm}^{2}\right)$ contains O_200 lying on PVDF_00-1.

Eint/s of models containing Pd and Pt NP lying on the PA and PVDF surfaces is on average $16 \times$ higher (i.e. weaker) than in the case of $\mathrm{CeO}_{2} \mathrm{NP}$ (Figures 3a and 3b). Pt NPs exhibit $23 \%$ lower $\mathrm{E}_{\text {int } / \text {, avg }}$ than Pd NP on all PA and PVDF surfaces, which corresponds to the difference in atomic layer distances $d_{h k l}$ based on the lattice parameters (3.891 $\AA$ for $\mathrm{Pd}, 3.924 \AA$ for $\mathrm{Pt}$ ). The lower lattice parameter indicates shorter and thus stronger bonds between atoms and consequently lower tendency to interact with other molecules. Eint/s trends of models containing Pd and Pt NPs are dependent on dhkl, as in cases of models with $\mathrm{CeO}_{2} \mathrm{NPs}$. The higher the dhkl, the lower the Eint/s (Figures 3a and 3b). Exceptions are models containing Pd_311 and Pt_311 (denoted as Pd_311_0 and Pt_311_0, respectively) on PA or PVDF surfaces, where the gaps between the lines of $\mathrm{Ce}$ atoms (of NP bases; Figure 1a) are parallel to the PA or PVDF polymer chains. This position allows the polymer chains of the surfaces to penetrate the NP bases gaps (Figure 1b), leading to increased attractive interactions between the NPs and PA and PVDF surfaces and consequently lower $E_{\text {int/s. While models }}$ containing Pd_311 and Pt_311 NPs show the highest Eints, models with Pd_311_0 and Pt_311_0 show the lowest Eints (Table 1). 


\section{CONCLUSION}

The modeling focused on $\mathrm{CeO}_{2}, \mathrm{Pd}$ and Pt NPs on the polymer surfaces of PA and PVDF. The strongest interactions are shown by $\mathrm{CeO}_{2} \mathrm{NP}$ with the highest $\mathrm{d}_{\mathrm{hkl}} \mathrm{Ce}$ _111 on PVDF_001, in the case of Pd and Pt NPs it is Pd_311_0 on PA_001 and Pt_311_0 on PA_100, respectively. $\mathrm{CeO}_{2} \mathrm{NPs}$ interact more strongly with PVDF surfaces than with PA surfaces due to the polar interactions, while Pd and Pt NPs interact more strongly with aliphatic parts of PA chains in PA_001 and PA_100 surfaces. The lowest average Eint/s,avg of all NPs having bases cleaved along (111) plane corresponded to the lowest atomic layers distance dhkl and the highest number of atoms per $\mathrm{nm}^{2}$. Within the types of surfaces, it showed on average the strongest interactions PA_001, PVDF_010 and PVDF_100 (comparable), in the case of NP types, it was Ce_111,Pd_111 and Pd_311_0 (comparable), Pt_111 and Pt_311_0 (comparable). Further research will clarify degrading effects against hazardous gases of NPs incorporated on the carriers.

\section{ACKNOWLEDGEMENTS}

\section{This work was supported by The Ministry of Education, Youth and Sports of the Czech Republic (projects SP2020/24 and LQ1602).}

\section{REFERENCES}

[1] MADUNA, K., TOMAŠIĆ, V. Air pollution engineering. Physical Sciences Reviews. 2017, vol. 2, no. 12, article no. 20160122.

[2] CHO, D., NAYDICH, A., FREY M.W., JOO, Y.L. Further improvement of air filtration efficiency of cellulose filters coated with nanofibers via inclusion of electrostatically active nanoparticles. Polymer. 2013, vol. 54, no. 9, pp. 2364-2372.

[3] JANOŠ, P., HENYCH, J., PELANT, O., PILAŘOVÁ, V., VRTOCH, V., KORMUNDA, M., MAZANEC, K. ŠTENGL, V. Cerium oxide for the destruction of chemical warfare agents: A comparison of synthetic routes. Journal of Hazardous Materials. 2016, vol. 304, pp. 259-268.

[4] CHEN, X., WANG, H., HE, J., CAO, Y., CUI, Z., LIANG, M. Preparation, Structure and Catalytic Activity of Pt-Pd Bimetallic Nanoparticles on Multi-Walled Carbon Nanotubes. Journal of Nanoscience and Nanotechnology. 2010, vol. 10, no.5, pp. 3138-3144.

[5] Dassault Systèmes BIOVIA, Materials Studio [software], Version 7.0, San Diego: Dassault Systèmes, 2020

[6] ČAPKOVÁ, P., ČAJKA, A., KOLSKÁ, Z., KORMUNDA, M., PAVLÍK, J., MUNZAROVÁ, M., DOPITA, M., RAFAJA, D. Phase composition and surface properties of nylon- 6 nanofibers prepared by nanospider technology at various electrode distances. Journal of Polymer Research. 2015, vol. 22, no. 6, article no. 101..

[7] GROOM, C.R., BRUNO, I.J., LIGHTFOOT, M.P., C. WARD, S.C. The Cambridge Structural Database. Acta Crystallographica Section B Structural Science, Crystal Engineering and Materials. 2016, vol. 72, no. 2, pp. 171179.

[8] HASEGAWA, R., TAKAHASHI, Y., CHATANI, Y., TADOKORO, H. Crystal Structures of Three Crystalline Forms of Poly(vinylidene fluoride). Polymer Journal. 1972, vol. 3, no. 5, pp. 600-610.

[9] SUN, H. COMPASS: An ab Initio Force-Field Optimized for Condensed-Phase Applications Overview with Details on Alkane and Benzene Compounds. The Journal of Physical Chemistry B. 1998, vol. 102, no. 38, pp. 73387364.

[10] VERNER, A., TOKARSKÝ, J. Molecular modeling study of antibacterial molecules on nylon 6,6 surfaces. Materials Today: Proceedings. 2020. https://doi.org/10.1016/j.matpr.2019.12.221

[11] PAULING, L. The Nature of the Chemical Bond and the Structure of Molecules and Crystals: An Introduction to Modern Structural Chemistry. Ithaca: Cornell University Press, 1960. 